\title{
Urgences
}

\section{Belluaire (extraits)}

\section{Michel Savard}

Numéro 14, août 1986

Corps et jouissances

URI : https://id.erudit.org/iderudit/025266ar

DOI : https://doi.org/10.7202/025266ar

Aller au sommaire du numéro

Éditeur(s)

Urgences

ISSN

0226-9554 (imprimé)

1927-3924 (numérique)

Découvrir la revue

Citer ce document

Savard, M. (1986). Belluaire (extraits). Urgences, (14), 59-64.

https://doi.org/10.7202/025266ar

Ce document est protégé par la loi sur le droit d'auteur. L'utilisation des services d'Érudit (y compris la reproduction) est assujettie à sa politique d'utilisation que vous pouvez consulter en ligne.

https://apropos.erudit.org/fr/usagers/politique-dutilisation/
Cet article est diffusé et préservé par Érudit.

Érudit est un consortium interuniversitaire sans but lucratif composé de l’Université de Montréal, l'Université Laval et l'Université du Québec à Montréal. Il a pour mission la promotion et la valorisation de la recherche. https://www.erudit.org/fr/ 


\section{Michel Savard}

\section{BELLUAIRE (EXTRAITS)}

La plupart des êtres s'adonnent au mirage d'une double croyance: ils croient à la pérennité de la mêmoire (des hommes, des choses, des actes, des nations) et à la possibilité de réparer (des actes, des erreurs, des péchès, des torts). L'une est aussi fausse que l'autre. La vérité est juste à l'opposé: tout sera oublié et rien ne sera réparé.

Milan UNDERA 


\author{
j'attends César Auguste \\ j'attends je goûte \\ de la société romaine \\ avec ses convois ses exploits \\ parcourus d'électricité avec \\ ses tribuns à vapeur \\ qui s'abreuvent de renard \\ avec ses carcasses vivantes \\ se reproduisant barbares et joyeuses \\ au long des passages visionnaires \\ et des descentes en flammes \\ dont la nuit s'intoxique \\ j'attends César Auguste \\ aspirant à pleins poumons \\ ce qu'il reste dans l'air \\ d'air à boire j'attends je gonfle \\ les muscles de ma littérature \\ à la fenêtre volent les voiles \\ qu'agite la bourrasque \\ insistante
}


je tremble encore

les rivages c'est à peine

s'ils contiennent les formes

que je n'assume qu'à contre-coeur

autre victime de cet univers trop physique

tu comprends la loi de la relativité

pour peu que tu l'appliques

à l'espacement des meubles dans le palais

à l'ordonnance de mes attentions ou encore

à ces spasmes qui nous font tributaires

coulant l'un en l'autre les obsessions

qui nous brûlent la gorge

qu'en penses-tu

César Auguste

sommes-nous de ces couples turbines

qui fusionnent quelque part quelque temps

sans jamais s'en remettre sommes-nous

tout à fait déments de trop croire

en ce qui ne s'explique que mal

ou pas du tout je tremble encore

et tu vas dire que j'exagère mais

César Auguste j'ai besoin

que tu me répètes que je suis un bon chien que

jamais tu n'as vu mon semblable 
tends à l'épuisement ta coupe

qu'il communie à ces plongeons

vers le mystère que consume ton corps

tends ta coupe à ceux qui n'ont plus soif

et néanmoins toujours en redemandent

pour faire à l'oubli ample mesure

daigne ô César Auguste

car ceux qui vont mourir

subiront sans frémir la griffe et le trident mais reculent d'effroi

devant cette vipère que tu réchauffes

sous chaque prédiction des augures 
c'est qu'il ne suffit plus

de bardasser l'un contre l'autre

et contre soi-même ses nuits blanches

à démontrer lequel de l'autre bande contre nature

laisse-moi te dire César Auguste

qu'elle a vite épuisé cette folie

son commentaire

alors que sur le sable à peine maculé

subistent quand même deux êtres

à renifler les sels qu'automatiques leurs coqs

leur passent sous le nez

sinon c'est semblable

mais d'autre chose 
on imagine avec ses fours une cité ses maladies sémantiques ses larmes furieuses dans les thermes de lieux publics où l'image encore esclavagiste ne pillerait pas une cité ses foules écumantes brandies en gradins par l'arène de pierre où tout serait permis où nous seraient offerts la chance d'accéder à la célébrité le choix des armes à toute épreuve qui nous assureraient ici d'atteindre nos objectifs fussent-ils ou non débattus sauvagement le long des clôtures au-dessus desquelles papillotteraient les cris et fulgurante la vision des lauriers 